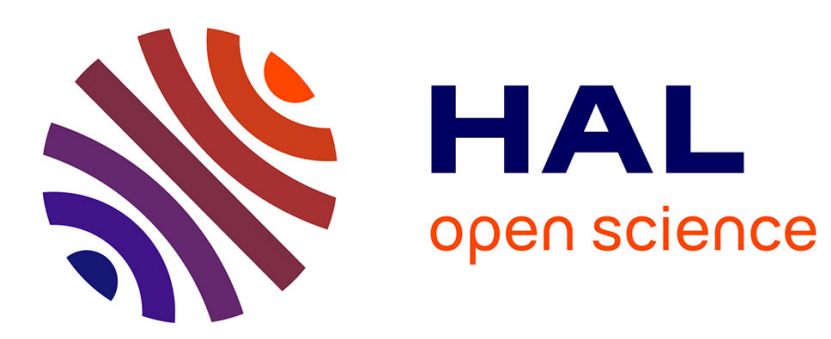

\title{
Developing a quality assurance metric
}

Steve Love, Rosa Scoble

\section{- To cite this version:}

Steve Love, Rosa Scoble. Developing a quality assurance metric. Active Learning in Higher Education, 2006, 7 (2), pp.129-141. 10.1177/1469787406064749 . hal-00571945

\section{HAL Id: hal-00571945 \\ https://hal.science/hal-00571945}

Submitted on 1 Mar 2011

HAL is a multi-disciplinary open access archive for the deposit and dissemination of scientific research documents, whether they are published or not. The documents may come from teaching and research institutions in France or abroad, or from public or private research centers.
L'archive ouverte pluridisciplinaire HAL, est destinée au dépôt et à la diffusion de documents scientifiques de niveau recherche, publiés ou non, émanant des établissements d'enseignement et de recherche français ou étrangers, des laboratoires publics ou privés. 


\title{
Developing a quality assurance metric
}

A panoptic view

\author{
STEVE LOVE \& ROSA SCOBLE Brunel University, UK
}

ABSTRACT There are a variety of techniques that lecturers can use to get feedback on their teaching - for example, module feedback and coursework results. However, a question arises about how reliable and valid are the content that goes into these quality assurance metrics. The aim of this article is to present a new approach for collecting and analysing qualitative feedback from students that could be used as the first stage in developing more reliable quality assurance metrics. The approach, known as the multi-dimensional crystal view, is based on the belief that individuals have different views on the benefits that the embedded process in a system can have on the behaviour of the system. The results of this study indicate that in the context of evaluation and feedback methods, the multi-dimensional approach appears to provide the opportunity for developing more effective student feedback mechanisms.

KEYWORDS: module evaluation methods, panoptic view, student feedback

\section{Introduction}

Student feedback and their evaluation of the teaching provision that they receive are crucial elements in the quality assurance process (Church, 2001). The Quality Assurance Agency (QAA) states that it is essential that there is a 'dialogue' between students and the people who teach them and supervise their work (QAA, 2004). They emphasize the importance of both qualitative and quantitative feedback from students as part of an overall strategy of 'enhancement and continuous development' on the part of teachers. Therefore, evaluation of teaching provision is a crucial part of our jobs as academics. Ramsden (1992) emphasized the importance of reflection for the teacher, and with the advent of the QAA review one can see that developing strategies for ascertaining effective and informative feedback from students on teaching provision has been taken on at an institutional as well as the individual teacher level. 
There are a variety of techniques that we use to get feedback on our teaching: self-monitoring, audiotape/videotape, information from students (in the form of questionnaires), students' coursework results and exam results and outside observers (peer observation). Indeed, in recent years there have been several publications designed to provide "best practice' guides for teachers and institutions (e.g. Learning and Teaching Support Network [LTSN] Assessment Guide, 2004; Evaluation Cookbook, 1999; Brennan and Williams, 2004). According to Fink (1995), the best feedback we can get on our teaching methods and assessment methods comes from students. They are in the unique position to carry out this evaluation as they experience first hand the effects of our teaching. Bearing this mind, the primary methods for collecting feedback from students come via questionnaires and interviews.

Questionnaires are the most common method used to get feedback on our teaching from students in the UK (Cowan et al., 2002). Typically, they contain questions relating to aspects of the module delivery (e.g. study guide for the module, printed handout, module resources), quality of feedback from the lecturer (e.g. in lectures, on coursework, to individual enquiries) and also some information from the students themselves (e.g. educational background, attendance at lectures). Questionnaires can be administered to students at any time but the main advantage of asking students to complete them at the end of term is that they can fully evaluate the learning activities they carried out during the module and evaluate the overall module. In addition, questionnaires have the benefit of anonymity on the part of the student, as they may otherwise be put off offering a criticism of the module for fear of 'staff reprisals'. However, Wilkinson (2003) points out that this approach has several weaknesses such as the superficial data it may provide from some students owing to the nature of the questions asked and the fact that some students may suffer from what she terms 'questionnaire fatigue' as a result of the number of questionnaires they are asked to complete each year.

Interviews, on the other hand, provide the opportunity for more in-depth feedback about the module and the academics involved in the teaching of this module. One drawback of this approach could be that students may feel awkward about the loss of anonymity (i.e. the student may be sitting in a one-to-one situation with the interviewer) in discussing aspects of the course and its delivery unless they have a good rapport with their teacher. An immediate solution to this would be to get a third party to conduct the interviews. One of the major advantages of the interview approach is that students can often highlight strengths or weaknesses of the course materials and module delivery that the interviewer had not anticipated beforehand. This would allow for further exploration of these topics in the course of the 
interview. The focus group is another technique that has been used to gather student feedback (Wilkinson, 2003). This approach provides the opportunity for a broad range of views to be gathered from students and discussed in depth. This benefit is acknowledged by Robson (1993) who stated that focus groups potentially offer more in-depth and qualitatively rich feedback from students in contrast to the information collected from questionnaires.

A key factor in the success of any of the methodological approaches highlighted above is the generation of appropriate information from students that can be subsequently used to improve their experience at the module level, programme of study level and ultimately at the university level. For example, how many departments evaluate the design of their module feedback forms on a regular basis to ensure that they provide students with the opportunity to comment on the major issues that have affected their perception of the module they have just studied? The aim of this article, therefore, is to present a new approach for collecting and analysing qualitative feedback from students (and staff), that could be used as the first stage in the development of a more formal feedback mechanism such as a focus group or questionnaire, to ensure all the major factors relating to quality assurance assessment are highlighted.

\section{Our methodological approach}

The novel approach that we are proposing, known as the multi-dimensional crystal view, is based on the belief that individuals have different views on the benefits that the embedded processes in a system have on the behaviour of the system. The views may arise from the particular perspective or past experiences of the stakeholders, but will, in any case, influence their attitudes when engaging with the process and, therefore, the expected functioning of the system. The approach, using simple matrix structures, attempts to capture and analyse these views in order to present a number of statements, or panoptic views, that may give insight on how effectively the system operates (Paul and Scoble, 2003; Scoble, 2002). Since this approach attempts to collate and compare qualitative information from a number of different sources, it is necessary, to make any of the views comparable, to have a methodology that narrows the collection of views to very specific parts and process. This is achieved by selecting a number of key processes and asking the stakeholders to assess their impact on key expected outcomes. In this approach the stakeholders are called 'points of observation' and the key processes are called 'drivers' while the key expected outcomes are called 'areas of interest'. This can be seen as a microanalysis of the interactions between processes and outcomes, or drivers and 
areas of interest, as viewed by each stakeholder, and can be compared with looking through a crystal and describing the reaction created when rays of light hitting from different directions meet somewhere within the bound crystal. Each stakeholder may look from a different angle of the crystal and what is seen is a particular combination of rays of light, or drivers and areas of interest. The panoptic view is achieved when these micro-analyses are aggregated into single statements that encompass and contrapose different perceptions of the systems' efficacy and efficiency.

\section{A matrix tool for analysis}

The use of a matrix as the analytical tool allows for an effective and 'tidy' collection of the stakeholders' view of the drivers and the areas of interests. Rows will identify the drivers, the key processes, while the columns will identify the areas of interest, the key outcomes. Each point of observation, stakeholder, will complete a matrix by giving a statement on their own view of how each driver impacts on each area of interest. The completed matrices can then be aggregated to create one single statement for each cell of the matrix that will encompass the views of each stakeholder. Insight and knowledge will then emerge from further interim aggregations concluding in one single statement on the behaviour of the system. The choice of such a tool is the ability to switch very easily between detail and summary while maintaining all the initial information. The matrix is also conducive to the use of colour coding to give a visual aid in the presentation of interim aggregations and final general statements (see Figure 1).

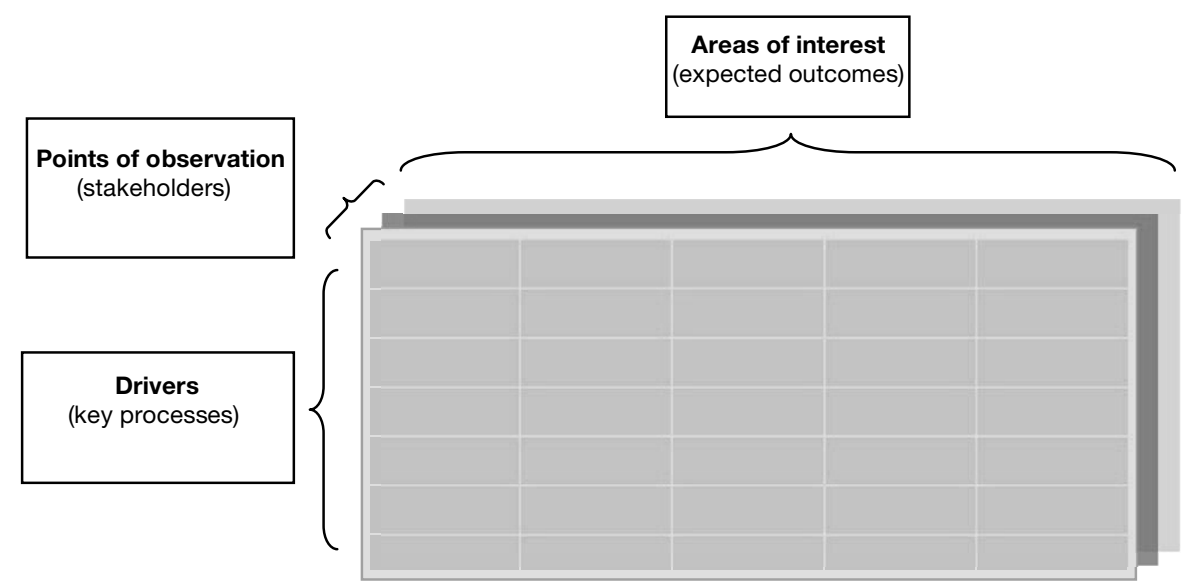

Figure 1 The use of the matix tool for analysis 


\section{The presentation tool: windows style and colour coding}

The colour coding used for the presentation of the results of the aggregation allow for rapid interpretation. After each aggregation the cell containing the summary statement will be colour coded according to the overall judgement of the specific drivers on the area of interest. For example, in the case of the negative judgement from a point of observation on the impact of a driver on a specific area of interest, the cell containing the statement will be colour coded light blue. For simplicity there are only 3 colours: light blue for a negative impact, pale blue for a positive impact and no colour for no causal effect, in other words, no impact. The colour coding is also used when aggregating results. In case of aggregation of contradicting perceptions the cell will display an amount of colour proportional to the collated judgement. For example, a prevalence of light blue will indicate a prevalence of negative perceptions. A step-by-step process regulates the building of the matrix, the assemblage of the matrices for each point of observation and the aggregation process.

\section{The process}

The matrix is built step-by-step by first selecting the drivers, areas of interest and points of observation and by preparing the sample matrix by inserting the drivers as row headings and the areas of impact as column headings. The second step is to define the framework, or question table, for the collection of the information as a series of questions, one per cell, to pose to the individual selected or points of observation. Each question relates only to the row and column it refers to, i.e. to the interaction between a specific driver and a specific area of interest. The third step is to fill in each cell on each table, one per point of observation, according to the coordinates (driver and area of interest) with a statement of that particular interaction. The statements are a form of judgement of the consequence of the driver on the area of impact as perceived by the point of observation. Each cell is colour coded according to the judgement presented. The fourth step is to aggregate each point of observation matrix on each interaction into one summary matrix. The summary statement of each single matrix will be collated into a new summary statement in the new matrix. The cells in the new matrix will be colour coded according to the summary judgement presented.

The fifth step is to aggregate all summary statements on each of the remaining two dimensions. The first dimension to be considered is the areas of interest. The result is a table with one column summarizing for 
each driver its general impact on the system. Therefore, for each driver there will be only one summary statement that will encompass its impact on all areas of interest as viewed by the points of observation. Colour coding is applied according to the summary judgement. The same process is adopted for the aggregation of all drivers. The resulting table will have just one summary row that will encompass, for each area of interest, the impact of the drivers of the process as viewed by the points of observation. Colour coding is applied according to the summary judgement. The sixth and last step is to aggregate all summary statements of the impact of the drivers on the areas of interest. This will result in a single statement that generalizes, in the case study reported in this article, the impact of the drivers of the final year project process on areas of interest viewed by different points of observation. Colour coding is applied according to the summary judgement.

\section{Matrix construction}

The matrix is progressively constructed by selecting and inserting driver and area of interest in the rows and column of the matrix. Drivers are selected from the key processes of the Final Year Project module. In this model these were identified as:

- the impact of the project assigned to or selected by the student

- the impact of the intermediate assessments and their feedback - tasks

- the impact of the 1st supervisor and 2nd reader - supervision.

The drivers are the key processes that define the final year project module. In terms of the project definition, the first stage of the final year project process is to define the project that the student will undertake. In relation to this, students have two options; they can choose a project proposal put forward by a lecturer or they can submit their own project proposal and hope that they will find a supervisor who is willing to supervise this project. The second driver is the deliverables associated with this module. In this case, students have three pieces of coursework to submit. Task 1 requires students to submit a project definition report. In this report students are asked to define the project in terms of its aims, objectives, the methods they will use to carry out the project (e.g. requirements gathering, evaluation) and a project plan. For Task 2, students are required to create an A1-sized poster presentation. The student uses the poster to give a 10 minute presentation to their supervisor and second reader. They will then be asked questions in relation to this. The idea behind this is to give students midterm feedback on their project. Task 3 is the project report itself. This should be a report of approximately 10,000 words in length. 
The final driver is supervision. The student has a supervisor whom they should meet with on a regular basis for guidance and advice on their project. In addition, the student has a second reader who marks their three pieces of coursework (apart from Task 1, the supervisor also marks the student's other two pieces of coursework). These are highlighted in Table 1.

Areas of interest are selected from the key outcomes of the Final Year Project module. In this model these were identified as:

- how the drivers impact on the quality of the project and consequential grade - quality/grade of the project

- how the drivers impact on the learning outcomes - learning outcomes.

The areas of interest for the final year project were self-selecting. For students, and staff, the quality of the project is of the utmost importance as this will have a direct impact on the grade that they receive for their final year project. The other areas of interest are the learning outcomes. For a project to pass it must meet the learning requirements set out in the study guide. For a project to receive a good grade it must, therefore, not only meet these requirements but exceed them. Information on how students can achieve this are defined in the assessment criteria for each of the three assessed tasks. These are listed in Table 2.

Points of observation are selected from the key stakeholders of the Final Year Project module. In this model these were identified as:

- students' perception of the impact of the drivers on the areas of interest - students

\section{Table 1 Drivers of the Final Year Project process}

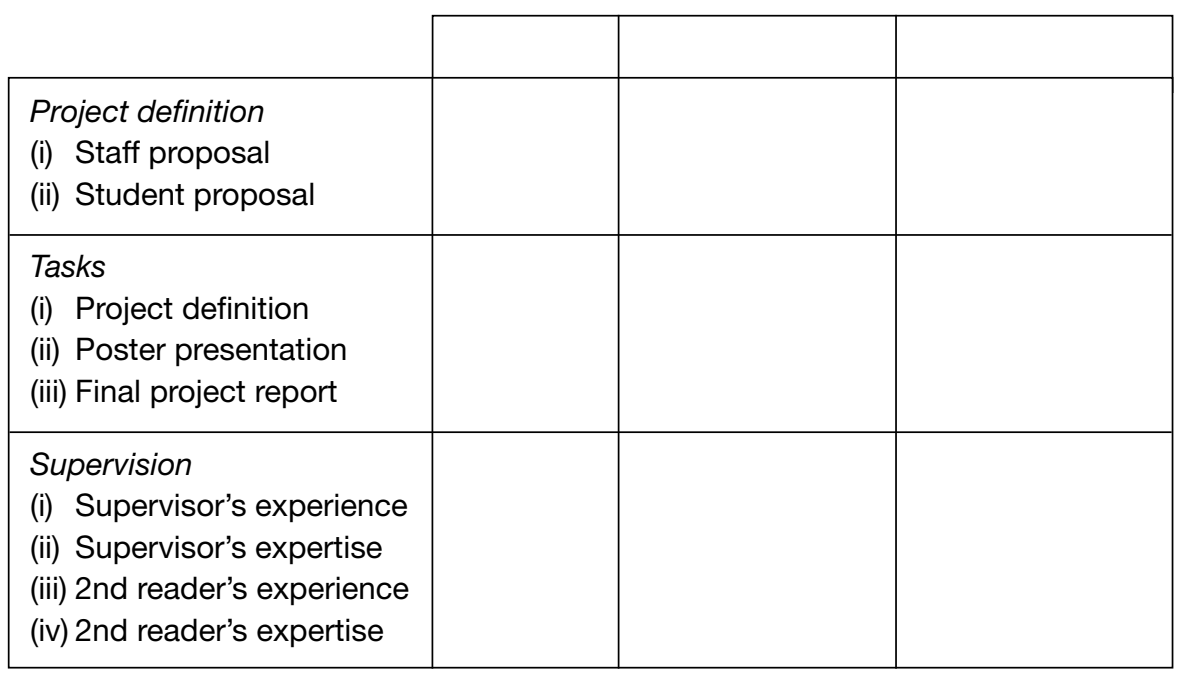


Table 2 Areas of interest for the Final Year Project process

\begin{tabular}{|l|l|l|l|l|l|}
\cline { 2 - 5 } \multicolumn{1}{c|}{} & $\begin{array}{l}\text { Quality of } \\
\text { project }\end{array}$ & $\begin{array}{l}\text { Project } \\
\text { management }\end{array}$ & $\begin{array}{l}\text { Problem } \\
\text { solving }\end{array}$ & $\begin{array}{l}\text { Design } \\
\text { approach }\end{array}$ & $\begin{array}{l}\text { Evaluation } \\
\text { of solution }\end{array}$ \\
\hline $\begin{array}{l}\text { Project definition } \\
\text { (i) Staff proposal } \\
\text { (ii) Student proposal }\end{array}$ & & & & & \\
\hline $\begin{array}{l}\text { Tasks } \\
\text { (i) Project definition } \\
\text { (ii) Poster presentation } \\
\text { (iii) Final project report }\end{array}$ & & & & & \\
\hline $\begin{array}{l}\text { Supervision } \\
\text { (i) Supervisor's experience } \\
\text { (ii) Supervisor's expertise } \\
\text { (iii) 2nd reader's experience } \\
\text { (iv) 2nd reader's expertise }\end{array}$ & & & & & \\
\hline
\end{tabular}

- supervisors' perception of the impact of the drivers on the areas of interest - supervisors.

The final dimension to this matrix is the points of observation. In the case of the study reported in this article, there are two points of observation: the students' and the academic members of staff perspectives.

\section{Method of collection for the points of observation}

A question table is used to guide the analyst through the collection of the different points of observation. For example, participants were asked questions such as, 'does choosing a project proposed by staff affect the final grade?' The points of observation were collected by personal interviews. Each interviewee was asked to respond to the questions from the question table. A statement that summarises the interviewee's position is then entered in the corresponding cell and an appropriate colour coding is applied with the definitions given in Table 3 .

Table 3 Definitions of cell coding

Positive effect - opinion cell coloured pale blue

Negative effect - opinion cell coloured light blue

No causal

no colour 


\section{Data collection}

For the purposes of the study reported here, three academic members of staff and three students were recruited to take part in the study. The students had just recently completed their final year project and received their final feedback for it. The questions were asked by the second author as she did not have any direct involvement with the final year project process. This seemed the experimentally valid option to take given what was mentioned in the introduction to the article about students (and perhaps even staff members) feeling uncomfortable about making their views known about a module to the module leader. All participants were informed that the data collection would be aggregated in the write up of the study and, in addition, that it would be anonymized. In addition, all participants were informed that they could receive a copy of the report once it had been written up or could contact the researchers if they had any subsequent questions in relation to the study.

\section{Results of study}

The results obtained from this methodological approach are presented in Table 4, which provides a 'panoptic view' by aggregating the responses from both sets of stakeholders (students and staff). From the results obtained from this approach, it appears that there are differences in student and staff perceptions, especially in relation to project supervision. Here, students feel it is important that members of staff have the appropriate experience to supervise their project effectively, whereas members of staff believe that it is the student's motivation to carry out the project and meet their deadlines that is the most important factor in conducting a successful project.

In addition, students believe that the feedback that they receive from their supervisors in relation to task 1 (project plan) and task 2 (poster presentation) is important for the successful development of their project. However, they also feel that is quite confusing if they appear to be getting contradictory feedback from their supervisors for these tasks. The students stated that it leaves them confused about which set of feedback comments they should follow. In relation to Task 3 (the final report) students were happy to get their grade and review the comments from their supervisor and second reader but felt that, by and large, these comments were redundant because they had already finished their project at this stage and could not make any changes to it.

Apart from assessing the actual content of the feedback, another important aspect to consider is the efficacy of this approach as a mechanism for 
Table 4 Panoptic view of student and staff responses

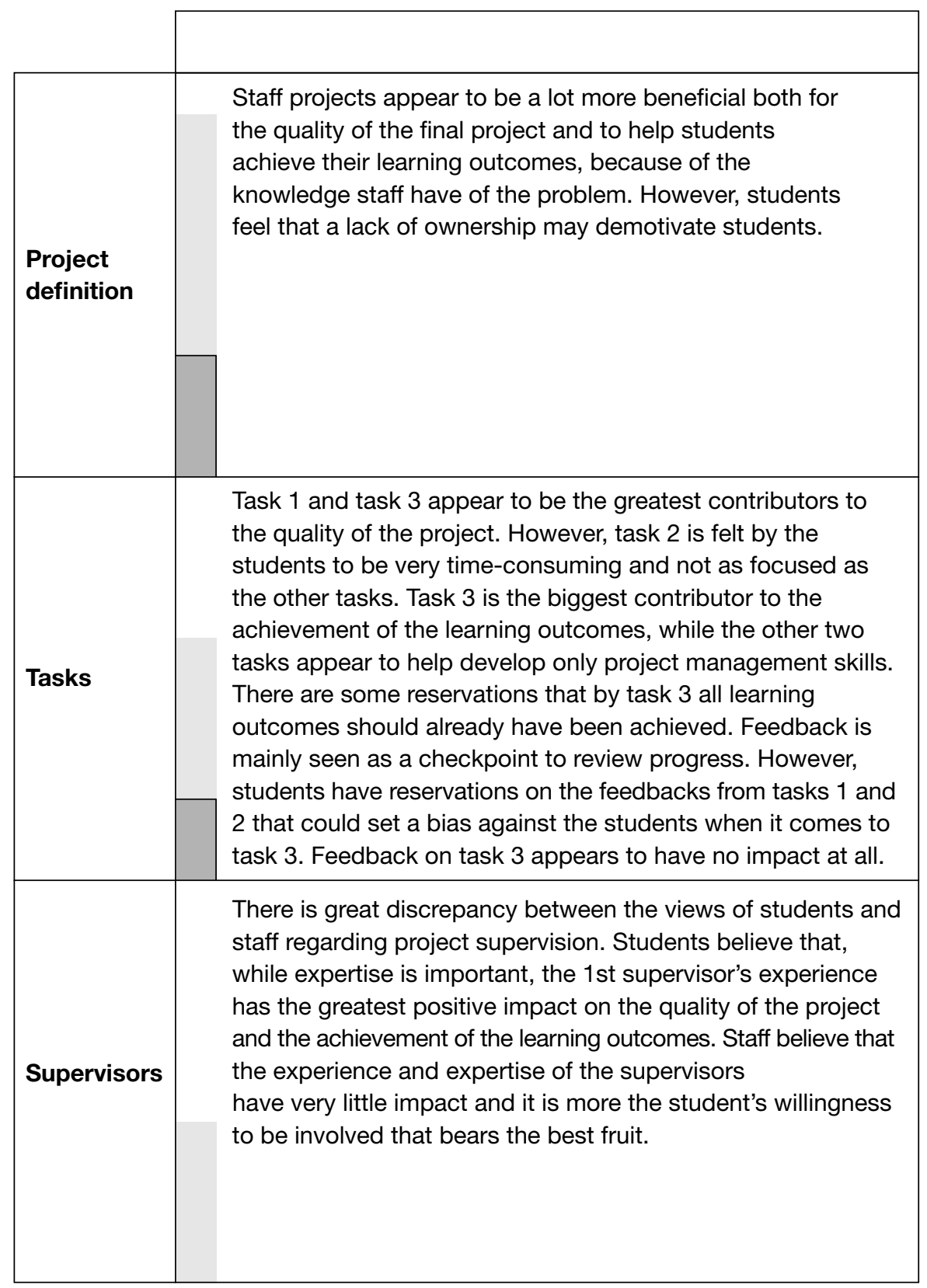


generating more reliable and valid topics to be included in quality assurance mechanisms (such as questionnaires and semi-structured interviews) to obtain feedback from students. For example, when this matrix was compared to the formal feedback questionnaire for this module, it became apparent that this approach offered students the opportunity to provide more in-depth information on issues not addressed by the formal methods, such as perception of the quality of feedback provided by the supervisor and second reader.

In addition, the use of the colour coding scheme highlights the important areas of concern that could be included in any formal quality feedback methodology. Although this could be seen as a crude attempt at producing categorical data, the small data set has allowed for the collection of in-depth qualitative data.

\section{Discussion}

According to the QAA, it is important that teachers obtain feedback from students on their perception of course provision in order to continually enhance and develop their learning experience. The aim of this article was to adopt a novel approach for this evaluation and feedback process that could ultimately be used as the first stage in developing more reliable quality assurance metrics. At one level, in terms of evaluating our own final year project process, this new approach of eliciting feedback from students has highlighted one important area that needs to be addressed. This is the set of feedback comments that students receive from their supervisor and second reader, especially for Task 1 and Task 2 . In order to rectify this potential area of confusion we propose that, in future, members of staff will produce an 'agreed' set of feedback comments in order to provide the student with a clear set of guidelines and suggestions on how they can develop their project to ensure that it meets the required learning outcomes. This is very salient as Gibbs (1993) stressed the importance of feedback for helping lecturers to improve students' educational experience.

In terms of a methodological approach to generating reliable and valid content for quality assurance metrics this approach has provided some indication that it has value. Heywood (2000) expressed concerns about questionnaire feedback from students being uninformative and not relevant to the particular module that the students were asked to assess. Our approach seeks to address this concern by obtaining in-depth information from students thereby providing a mechanism for the development of metrics that produce focused and informative feedback. Having said this, there are limitations to the work reported here that will have to be addressed in future work. In order to improve the ecological validity of the 
findings reported here, there is a need to test this approach on a more representative sample of the student population in our department. In addition, future developments in this work should also include a comparison of our approach with a more traditional approach of categorical data collection and analysis. This is an important comparison to make as it will also allow us to assess the methodological efficacy of this approach.

Overall, it can be said that this approach offers the potential for obtaining more informative feedback from students in relation to quality assurance issues. This can only be seen as yet another positive move in the iterative process of enhancing and developing the quality and provision of teaching and supervision that we offer our undergraduate students.

\section{References}

brennan, J. \& Williams, R. (2004) 'Collecting and Using Student Feedback:

A Guide to Good Practice', HEFCE Report, May.

CHURCH, F. (2001) Students as Consumers: The Importance of Student Feedback in the Quality Assurance Process. 3rd Annual Conference of the Learning in Law Initiative, 4 January, University of Warwick: http://www.ukcle.ac.uk/lili/2001/ [accessed 15 April 2005].

COWAN, P., MORRISON, H., WYlie, C., MCbRide, F. V., LeE, M. \& GReenaway, G. (2002) 'Disseminating Standards in Higher Order Learning: Systemically Valid Instruments for Standards-based Reform’, Interactive Learning Environments 10(3): 217-41.

eVAluation cookbook (1999) JISC infoNet Service. http://www.jiscinfonet.ac.uk/ Resources/evalkit/toolkit-database/ev019/view [accessed 17th April 2005].

FIN K, L. D. (1995) ‘Evaluating Your Own Teaching', in P. Seldin (ed.) Improving College Teaching, pp. 191-203. Bolton, MA: Anker.

GIB BS, G. (1993) Improving the Quality of Student Learning. Bristol: TES.

HeYWood, J. (2000) Assessment in Higher Education. London: Jessica Kingsley. LTSN (2004) Enhancing Student Learning Through Effective Formative Feedback.

Report no. ASS096.

Paul, R. J. \& SCOble, R. (2003) Assessing the Assessment - A Panoptic View of the RAE. 15th International Conference on Assessing Quality in Higher Education (14-16 July, Cape Town, South Africa).

ROBSON, C. (1993) Real World Research: A Resource for Social Scientists and Practitioner Researchers. Blackwell: Oxford.

QAA (2004) Annual Report to the Higher Education Funding Council for England, http://www.qaa.ac.uk/aboutus/progress/hefcerep2005/content.asp [accessed 28 April 2005].

RAMSDEN, P. (1992) Learning to Teach in Higher Education. London: Routledge

SCOBle, R. (2002) Funding of Research in Higher Education: A Panoptic View of the RAE. Brunel University, London. PhD thesis.

Wilkinson, s. (2003) Delivering the Link: Using Student Feedback Studies to Improve Student Learning in Dissertation Studies. Building the Link Conference, Oxford Brookes University. 


\section{Biographical notes}

STEVE LOVE works in the School of Information Systems, Computing and Mathematics at Brunel University. His main research interests include online learning and distance learning. He also undertakes research in interaction design, the use of mobile technologies and ubiquitous computing.

Address: School of Information Systems, Computing and Mathematics, Brunel University, St John's Building, Kingston Lane, Uxbridge UB8 3PH, UK. [email: steve.love@brunel.ac.uk]

ROSA SCOBLE works in the School of Information Systems, Computing and Mathematics at Brunel University. Her main research interests include investigating performance indicators in higher education and research funding in higher education (with a particular focus on the Research Assessment Exercise).

Address: School of Information Systems, Computing and Mathematics, Brunel University, St John's Building, Kingston Lane, Uxbridge UB8 3PH, UK. [email: rosa.scoble@brunel.ac.uk] 